\title{
Controlled Rate Thermal Analysis (CRTA) as a Fast and Effective Method for the Development of Ceramic Powders of Synthetic Hydroxyapatite at Low Temperatures
}

\author{
Eduardo Peón 1,*iD, Gastón Fuentes ${ }^{1}$ (i) , Juan C. Galván ${ }^{3}$ (D) \\ 1 Department of Ceramic and Metallic Biomaterials, Biomaterials Center, University of Havana, Ave Universidad s/n, \\ Havana, 10400, Cuba; epeonaves@gmail.com (E.P.A.); gastonfe@ biomat.uh.cu (G.F.E.;) \\ 2 National Center for Metallurgical Research (CENIM) CSIC, 28040 Madrid, Spain; jcgalvan@ @enim.csic.es (J.C.G.); \\ * Correspondence: epeonaves@gmail.com;
}

Scopus Author ID 9235421100

Received: 20.10.2020; Revised: 12.11.2020; Accepted: 14.11.2020; Published: 16.11.2020

\begin{abstract}
One of the main limitations for applying synthetic hydroxyapatite as a filler in cement and other formulations in orthopedic surgery is its morphology. The present work shows the obtaining of synthetic hydroxyapatite powders at low temperatures such as 300 and $850^{\circ} \mathrm{C}$ using the Controlled Rate Thermal Analysis (CRTA) technique. The powders obtained were characterized by IR spectroscopy and X-ray diffraction, showing that the phase formed corresponds to crystalline hydroxyapatite. The specific surface area values determined are between 17 and $66 \mathrm{~m}^{2} / \mathrm{g}$ with a pore size between 50-300 $\AA$. The transformation of phases in the synthetic hydroxyapatite is studied by Dynamic Thermogravimetric Analysis and CRTA techniques, allowing the kinetic calculations of the transformation using two methods of data processing, determining the activation energy (Ea), preexponential factor (A), and model kinetic most likely in each stage. The results show the effectiveness and usefulness of the CRTA technique for preparing synthetic hydroxyapatite powders with different specific surface areas, which makes this technique attractive for medical purposes.
\end{abstract}

Keywords: hdroxyapatite; bioceramics; thermal analysis; controlled rate thermal analysis; specific surface; pore size.

(C) 2020 by the authors. This article is an open-access article distributed under the terms and conditions of the Creative Commons Attribution (CC BY) license (https://creativecommons.org/licenses/by/4.0/).

\section{Introduction}

Among the various materials currently used as substitutes for bone tissue, synthetic hydroxyapatite (HA) receives special attention for its bone-like properties and excellent biocompatibility. Morphology of commercial HA used in clinical and research applications has a pore size between 100 and $150 \mu \mathrm{m}$, an appropriate range to improve cell colonization and tissue growth when used in direct applications as bone substitutes [1-5]. The methods for obtaining HA's ceramics developed to date are varied [6-8]. The conventional method of chemical precipitation is the most widespread [9]. The synthesis by hydrothermal process and the combination methods are the most used after chemical precipitation [10-16]. However, the scientific community continues to search for alternative methods to obtain hydroxyapatites with better microstructural properties.

Despite the variety of methods for the synthesis of HA ceramics with a specific texture and its use as fillers in formulations for orthopedic surgery reported, the pore size's uniformity 
remains an unresolved problem [7, 17-19]. Compared to the aforementioned methods, the solgel synthesis of HA constitutes a promising alternative because it allows a mixture at the molecular level of the calcium and phosphorus precursors, improving the resulting HA's homogeneity [20,21]. In recent years, significant advances have been made employing the solgel technique for these purposes by different researchers and groups [22].

The treatment of phosphates at different temperatures causes changes in their properties, particularly in their physicochemical characteristics and chemical composition, making it possible to study the chemical composition of the mixtures obtained and the effect produced by the substitution that occurs between the fundamental elements. Then, in most experiments, the thermal treatment applied to the material is the biggest drawback due to the difficulties of controlling the pressure and temperature gradients in the different parts of the sample $[19,23,24]$.

The method known as "Control Rate Thermal Analysis" (CRTA), developed by Rouquerol [25, 26], has been used as heat treatment in formulations to achieve control of textures in solids [26-28]. For complex thermolysis that takes place through superimposed, parallel or serial reactions, heat treatment at controlled speed favors the formation of a homogeneous porosity and a homogeneous surface in its chemical composition and distribution of defects.

According to the above, the present study aims to obtain synthetic HA with a controlled specific surface and homogeneous pore distribution, where the CRTA technique carries out the crystallization process. These parameters have great importance when the HA is used as filler in the preparation of composites. In this case, the specific surface area should be small to avoid microfracture centers' presence, causing the formed material to be very brittle.

On the other hand, the possibility of evaluating the energy consumption necessary for a transformation or to determine the adequate thermal treatment in obtaining a product, the activation energy $(\mathrm{Ea})$ of the chemical reactions involved and the mechanism by which these take place; besides helping to understand these processes, it allows to scientifically evaluate the propitious conditions from the technological point of view to obtain material.

\subsection{Theoretical basis of the crystallization kinetics of hydroxyapatite.}

In the consulted literature, thermoanalytical studies of the transformations in the thermal treatments of the formation of the bioceramics are hardly reported, as well as the determination of the kinetic and thermodynamic parameters of these transformations. Several authors studied the transformation of hydroxyapatite by x-ray diffraction (XRD) with temperature, Infrared Fourier Transform Spectroscopy (FTIR), and Thermogravimetric Analysis (ATG) [29-38]. They observed that samples heated up to around $600^{\circ} \mathrm{C}$, the mass decreases, but no changes were observed in the XRD patterns; however, above $700^{\circ} \mathrm{C}$, the material continues to lose mass, and the diffraction pattern indicates the crystallization of the HA, after dehydration and structural water loss according to:

$$
\begin{aligned}
& \mathrm{Ca}_{10-\mathrm{z}}\left(\mathrm{HPO}_{4}\right)_{\mathrm{z}}\left(\mathrm{PO}_{4}\right)_{6-\mathrm{z}}(\mathrm{OH})_{2-\mathrm{z}} * \mathrm{nH}_{2} \mathrm{O}=\mathrm{Ca}_{10-\mathrm{z}}\left(\mathrm{HPO}_{4}\right)_{\mathrm{z}}\left(\mathrm{PO}_{4}\right)_{6-\mathrm{z}}(\mathrm{OH})_{2-\mathrm{z}}+\mathrm{nH}_{2} \mathrm{O} \\
& \mathrm{Ca}_{10-\mathrm{z}}\left(\mathrm{HPO}_{4}\right)_{\mathrm{z}}\left(\mathrm{PO}_{4}\right)_{6-\mathrm{z}}(\mathrm{OH})_{2-\mathrm{z}}=\mathrm{Ca}_{10-\mathrm{z}}\left(\mathrm{PO}_{4}\right)_{6-\mathrm{z}}(\mathrm{OH})_{2-\mathrm{z}}+\mathrm{zH}_{2} \mathrm{O}
\end{aligned}
$$

without determining the stoichiometric coefficient $\mathrm{z}$, nor the quantity $\mathrm{n}$.

The use of thermal analysis techniques for kinetic studies brings experimental problems centered on the effective control of temperature and pressure gradients that originate in the 
sample product's volume of a given reaction, being present until they are adequately controlled. These gradients often lead to a false interpretation of the results, as well as to erroneous kinetic parameters.

The CRTA, designed experimental devices that acted on the furnace heating system to ensure quasi-equilibrium work conditions. Therefore, changes in temperature that result in an endothermic or exothermic nature in a reaction are linked to the heat capacity and thermal conductivity of the sample. The pressure differences between the inside and the outside of the sample will be reduced to a value compatible with the requirements of the experiment, keeping constant by reducing and maintaining constant reaction speed. Consequently, the kinetic analysis of the processes involved can be carried out with simplicity and precision.

The main aspect of these reactions is the process that involves an interface between the reactant and the solid product, which gives rise to a special kinetic, with features common to other types of reactions. For these reactions, the definition of reaction rate $\pm(1 / \mathrm{V})(\mathrm{dN} / \mathrm{dt})$ or \pm $(\mathrm{dC} / \mathrm{dt}) \mathrm{v}$, where $\mathrm{N}$ is the amount of reactant and $\mathrm{C}$ the concentration, is not applicable because the processes they do not take place in the volume of the substance, but at the boundary between the solid phases. The way to characterize the speed of these reactions is the progress of the reaction by the degree of transformation $(\alpha)$. The mechanism of it would be the model that best fits the description of its progress from the experimental results.

The algebraic functions of the reaction mechanisms described so far in the literature for studying reactions to the solid-state have been compiled by Romero [39-41]. These expressions represent the different interpretations of the reactions that occur to the solid-state: laws of nucleation, growth, and diffusion. Various methods have been described in the literature that permit the kinetic analysis of reactions in the solid-state [42,43]. Although the methods used are very varied, in this work, we used the differential methods that determine the function $\mathrm{f}(\alpha)$ from the equation of the speed of the reaction:

$$
\frac{d \alpha}{d T}=\left(\frac{A}{\beta}\right) \exp ^{\left(\frac{-E_{a}}{R T}\right)} f(\alpha)
$$

The best known are the Achar Method [44] and the Jerez Modification to the FreemanCarroll Method [45].

\section{Materials and Methods}

\subsection{Preparation of hydroxyapatite.}

The hydroxyapatite used in this study was prepared using a variant of the sol-gel method previously described by Dean Mo Liu et al. [20, 21]. The HA sol was prepared by mixing triethylphosphite (TEP), $\mathrm{C}_{6} \mathrm{H}_{15} \mathrm{O}_{3} \mathrm{P}$ (Aldrich, $98 \%$ ) and calcium nitrate tetrahydrate, $\mathrm{Ca}\left(\mathrm{NO}_{3}\right)_{2} * 4 \mathrm{H}_{2} \mathrm{O}$ (Aldrich) in aqueous phase as precursors of phosphorus and calcium, respectively. In a first stage of the process, the phosphorus precursor is hydrolyzed. The calcium precursor is then added in a $\mathrm{Ca} / \mathrm{P}=1.64$ molar ratio using an aqueous solution of calcium nitrate. Subsequently, gelation is achieved by evaporation of solvent at $80^{\circ} \mathrm{C}$, until a viscous liquid is obtained.

To carry out the samples' thermal treatment by CRTA, $1 \mathrm{~g}$ of each one is introduced into a programmable tube furnace Eurotherm with temperature error $\pm 1^{\circ} \mathrm{C}$ connected to a vacuum system through a diaphragm with an opening of $0.1 \mathrm{~mm}$. Through a software, it is possible to 
regulate the temperature and measure the pressure generated. This last parameter is the one that regulates the transformation rate. The principle of this treatment is to control the system's temperature and pressure to achieve a constant decomposition rate. Table 1 describes the different CRTA treatments' experimental conditions to establish the crystallization parameters of $\mathrm{HA}$ at the lowest temperature.

Table 1. Experimental condition for the HA powders by CRTA.

\begin{tabular}{l|c|c|c} 
Sample & $\mathbf{T}_{\mathbf{c}}\left[{ }^{\circ} \mathbf{C}\right]$ & $\mathbf{p}[\mathbf{m b a r}]$ & $\mathbf{T}_{\mathbf{e}}\left[{ }^{\circ} \mathbf{C}\right]$ \\
\hline CRTA-1 & 100 & 2.65 & 300 \\
\hline CRTA-2 & 100 & 0.50 & 300 \\
\hline CRTA-3 & 300 & 1.00 & 850 \\
\hline CRTA-4 & 300 & 0.33 & 850 \\
T - temperature of control of the pressure, \\
p- pressure of control, \\
Te - maximum temperature used to achieve such pressure control.
\end{tabular}

By comparison, the conventional heat treatment sample was performed at $950^{\circ} \mathrm{C}$ for 5 $\mathrm{h}$ in Eurotherm muffle with digital temperature control $\pm 1^{\circ} \mathrm{C}$.

The percentage of calcium was determined through absorption spectroscopy at $\lambda=$ $422.7 \mathrm{~nm}$ (Philips Pye Unicam SP9) and by emission spectrometry at $\lambda=213.6 \mathrm{~nm}$ (Perkin Elmer Capture 40) the percentage of phosphorus, from which the $\mathrm{Ca} / \mathrm{P}$ ratio was determine. The physical-chemical characterization of the powders was carried out by FTIR (PHILIPS FTIR PU 9800) using the KBr pellet and XRD (Philips Pye Unicam PW1710) by the powders method. The samples' thermogravimetry was performed on a Shimadzu with a heating rate of $10{ }^{\circ} \mathrm{C} / \mathrm{min}$ and an end temperature of $1200^{\circ} \mathrm{C}$. Powders morphology was examined by scanning electron microscopy (SEM) on a Tescan Vega TS 5130SB microscope. The porosity and specific surface of the material were determined by the BET method from the nitrogen absorption isotherms at a temperature of $77 \mathrm{~K}$.

\section{Results and Discussion}

\subsection{Characterization of the powders of hydroxyapatite.}

The prepared powders' chemical analysis showed that the $\mathrm{Ca} / \mathrm{P}$ ratio in all cases was 1.65 , which is an adequate value for apatite to maintain its structure after heat treatment.

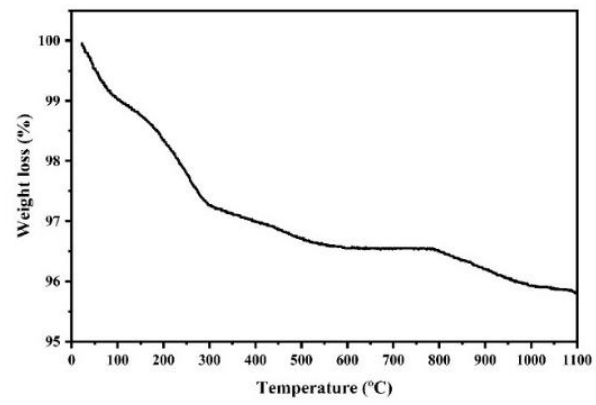

Figure 1. TGA of the HA without thermal treatment.

Reports of HA treatment using the CRTA technique are scarce in the scientific literature. For this reason, first, the TGA of the green HA was carried out (Figure 1) to know the characteristic temperatures of its thermolysis. The result showed a first stage associated with dehydration, and then two other stages corresponding to the dehydration-crystallization 
process. Although these processes have been reported by other authors [32, 34-36, 38], the influence of experimental conditions on the morphology of the final products achieved by CRTA have not been studied. Consequently, the CRTA (Figure 2) was used to verify the results initially obtained by TGA and to know exactly the temperatures and partial pressures characteristic for each step in the sample crystalization.

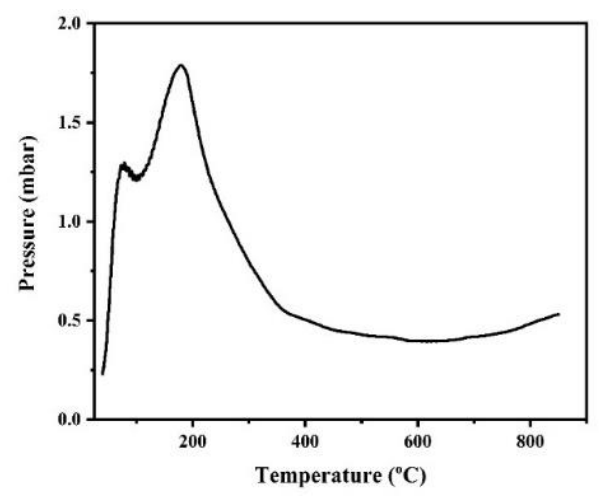

Figure 2. CRTA of a HA sample without thermal treatment.

On the other hand, the results observed from the IR spectra and the diffractograms show that a pure crystalline phase constitutes the HA powders obtained after conventional treatment and by CRTA.

The IR spectra shown in Figure 3 make it possible to compare the HA obtained by the conventional method (HA-CTT) and by the CRTA (CRTA-1 to CRTA-4). In all of them the presence of the characteristic bands corresponding to the fundamental vibrations 3571.46 and $631.73 \mathrm{~cm}^{-1}$ of the $\mathrm{OH}^{-}$and $v_{3} 1092.75$ and $1045.49 \mathrm{~cm}^{-1}, v_{1} 963.51 \mathrm{~cm}^{-1}, v_{4} 602.80$ and 568.08 $\mathrm{cm}^{-1}$ of the $\mathrm{PO}_{4}^{3-}[46,47]$. Although the spectra obtained are very similar, the band at 3571.46 $\mathrm{cm}^{-1}$ of the $\mathrm{OH}^{-}$vibration was only observed in the HA-green and HA-CTT samples corresponding to hydration water. The bands corresponding to the $\mathrm{PO}_{4}{ }^{3-}$ group in the CRTA-3 and CRTA-4 samples are narrower and symmetrical, indicating an increase in crystallinity according to other authors' reports [38, 48, 49].

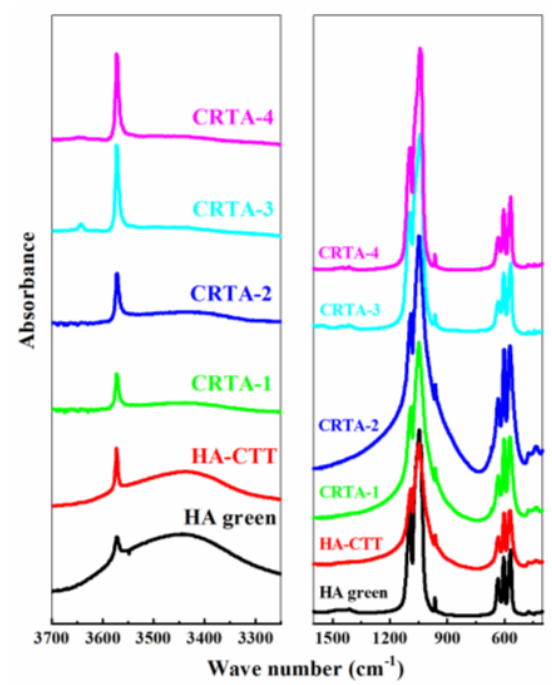

Figure 3. FTIR spectrum characteristic of HA green and after the thermal treatments.

The XRD patterns (Figure 4) show the characteristic peaks of HA for all cases, according to the International Center for Diffraction Data (ICDD) in file \# 01-074-0566 [50- 
52]. It should be noted that even for the CRTA-1 and CRTA-2 samples, despite having been treated at a maximum temperature of $300^{\circ} \mathrm{C}$, they crystallized in a pure hydroxyapatite phase.

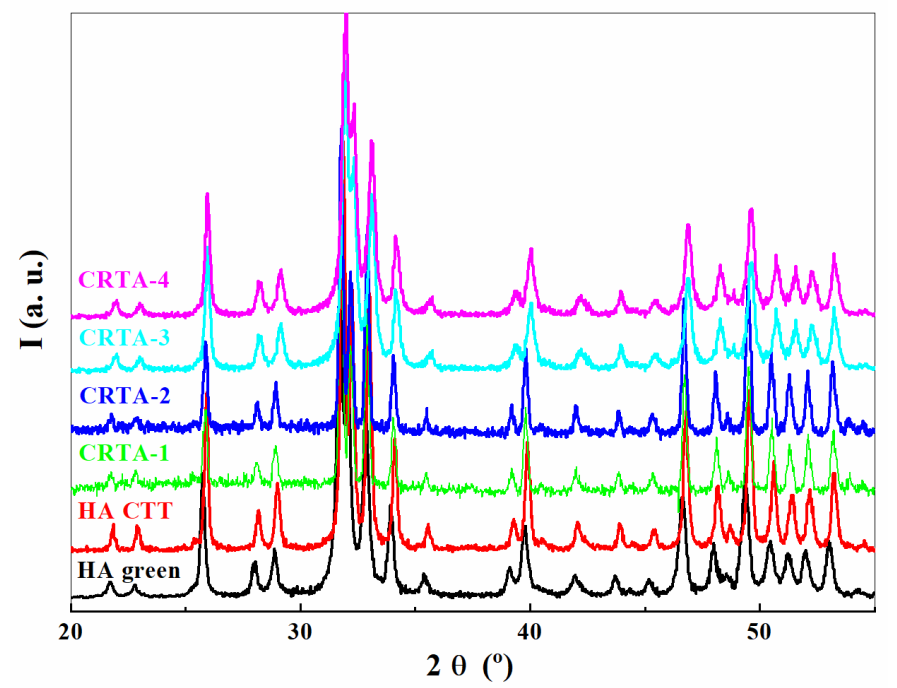

Figure 4. X-ray Diffraction pattern of HA green and after the thermal treatments.

Conventional heat treatment to obtain crystalline $\mathrm{HA}$ is carried out at $950^{\circ} \mathrm{C}$ for several hours. However, using CRTA at temperatures as low as $300^{\circ} \mathrm{C}$ crystalline $\mathrm{HA}$ is obtained as seen in Figures 5a and 5b. The HA obtained is made up of small white crystals that fuse to form a cluster because of the high surface/volume ratio of ultra-fine crystals produced by the heat treatment. Although the shape of the biological apatite grains is essentially needle-like, it is expected that by optimizing CRTA conditions, it will be possible to obtain a similar grain shape.

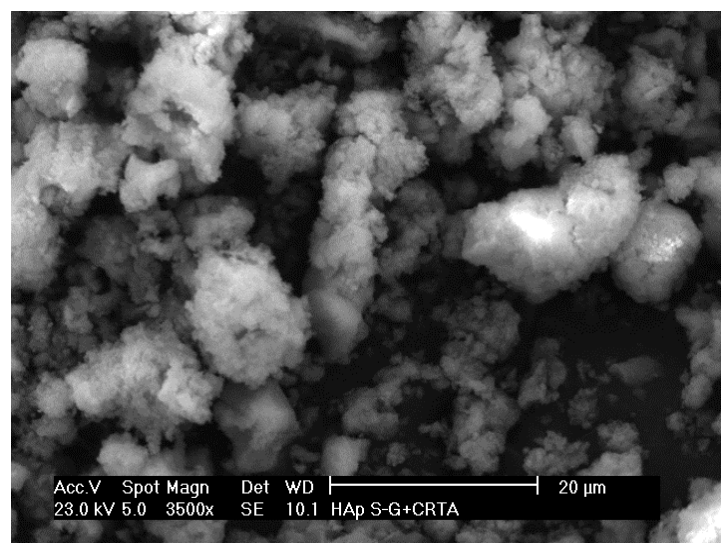

(a)

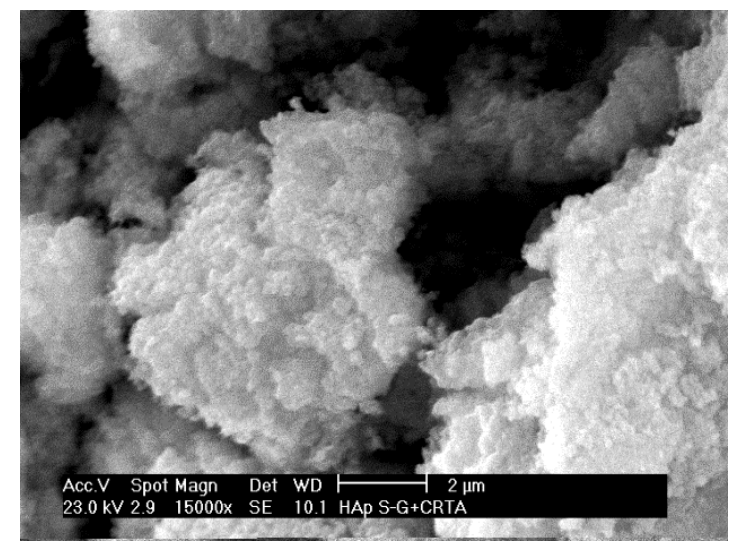

(b)

Figure 5. SEM micrographs of the HA-4 powder prepared using CRTA under different magnifications: (a) 3500x; (b) 15000x.

Table 2 describes the specific surface results measured by the BET method. It is observed that the range of specific surfaces in the CRTA samples is higher than in sintered powders with conventional heat treatment. In samples CRTA-1 and CRTA-2, it is observed that when the pressure in the process is increased, a significant increase in the specific surface area is produced, demonstrating an inversely proportional dependence. The same behavior is observed in the CRTA-3 and CRTA-4 samples, but in this case, not so marked. However, when comparing the CRTA-2 and CRTA-4 samples, a decrease in specific surface area is observed with increasing process temperatures. 
Table 2. Determinations by BET method of different HA powders by CRTA.

\begin{tabular}{c|c} 
Sample & S \\
\hline BET $\left(\mathbf{m}^{2} / \mathbf{g}\right)$ \\
\hline CRTAT & 14.0 \\
\hline CRTA-2 & 34.9 \\
\hline CRTA-3 & 66.7 \\
\hline CRTA-4 & 32.0 \\
\hline
\end{tabular}

Summarizing, with the use of the CRTA method, the HA decomposition processes are obtained with a better resolution when reaching quasi-equilibrium conditions in the thermolysis, eliminating the slow transfer of heat to the sample as a control parameter of the process of decomposition.

\subsection{Kinetic calculations in the crystallization of hydroxyapatite.}

Once the stages of the phase's transformation have been determined, their kinetics was studied by CRTA. For each of these stages, the pairs of $\alpha$ us T values necessary for the kinetic calculations were determined. For the data processing, a computer program was used, developed for this purpose, which allows the calculation of the activation energy (Ea), Arrhenius pre-exponential factor (A), and most probable mechanism, applying the Jerez and Achar method. This program allows selecting the most probable mechanism for the reaction between the 24 possibles. The mechanism that showed a better graphic fit to the Jerez method

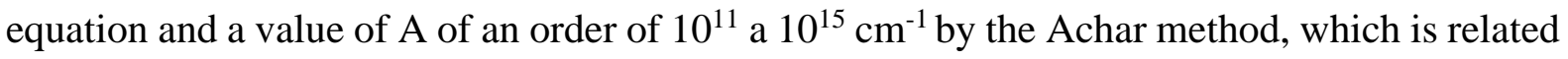
to the frequency of vibration of the crystalline networks in a solids reaction, were selected. The results are summarized in Table 3.

Table 3. Kinetic results in the formation of the HA.

\begin{tabular}{l|c|c|c} 
& Ea $(\mathbf{k J} / \mathbf{m o l})$ & $\mathbf{A}$ & Mechanism \\
\hline 1st stage & 76.3 & $1.7 * 10^{11}$ & D5 \\
\hline 2nd stage & 282.2 & $5.4 * 10^{11}$ & G6
\end{tabular}

As expected for this type of process, in the first stage, the most probable mechanism was D5, which corresponds to diffusion with decreasing the reactant activity. The limiting step of the speed of transformation is also the speed of diffusion of the gaseous product of decomposition through the layer of product in the formation. For the second stage, a G6 type mechanism was verified, three-dimensional nucleus growth, which suggests forming a new crystalline phase by no diffusive means.

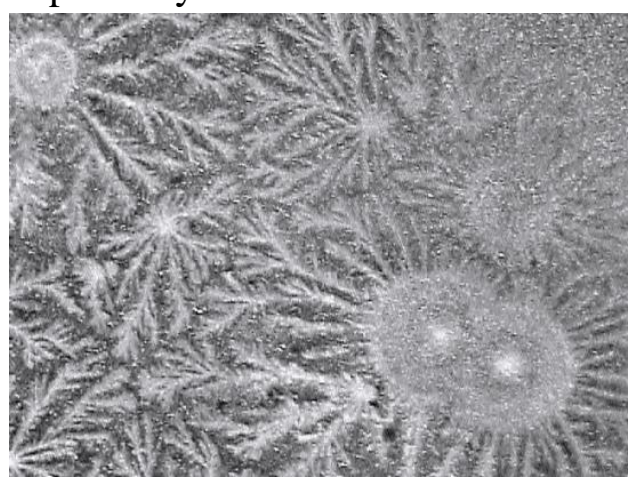

(a)

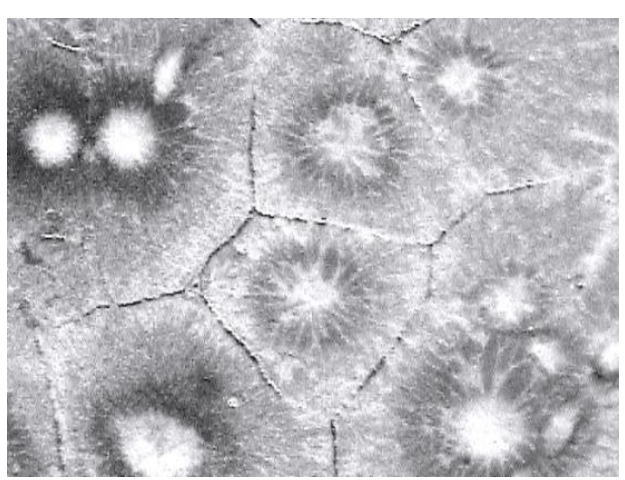

(b)

Figure 6. Morphology of HA powders at the different kinetic calculations: (a) Crystallized at $300^{\circ} \mathrm{C}$; (b) Crystallized at $450^{\circ} \mathrm{C}$.

The HA powders, crystallized at each of the stages' characteristic temperatures, were observed by MO. It was found that above $300^{\circ} \mathrm{C}$, only the growth of small HA crystals from 
multiple nucleation centers is observed (Figure 6 a), confirming that the most likely mechanism by which crystallization occurs is of the D5 type. The progressive increase in temperature shows that HA's complete crystallization between 360 and $580^{\circ} \mathrm{C}$ and the maximum reaction rate at $450^{\circ} \mathrm{C}$ with a G6 mechanism (Figure 6b).

As observed in Figures $6 \mathrm{a}$ and $6 \mathrm{~b}$, the HA obtained is composed of small crystals, which merge and consequently form aggregates. This phenomenon could be attributed to a high surface area and volume of ultrafine crystals related to CRTA heat treatments. It should also be noted that the crystals' shape mostly exhibits a needle-like structure, similar to biological apatite.

\section{Conclusions}

The effectiveness and usefulness of the CRTA technique for obtaining synthetic hydroxyapatite crystalline powders with controlled specific surface areas was demonstrated in the present work. Samples obtained by CRTA were pure crystalline HA, verified by IR spectroscopy and XRD. It was observed that there is a dependence of the specific surface with the pressure and temperatures used, achieving a surface area range of 14 to $66 \mathrm{~m}^{2} / \mathrm{g}$. Crystalline HA was achieved at temperatures as low as $300^{\circ} \mathrm{C}$.

As a result of this research, the CRTA technique's feasibility to study reactions in condensed phase systems was demonstrated. The present work confirmed that the dehydrationcrystallization process of HA takes place in two stages: 1st - By a D5 mechanism, with an activation energy of $76.3 \mathrm{~kJ} / \mathrm{mol}$, is characterized by the diffusion of gaseous products; $2 \mathrm{nd}$ By a G6 mechanism, with an activation energy of $282.2 \mathrm{~kJ} / \mathrm{mol}$, characterized by the growth of the nuclei of the new phase formed.

\section{Funding}

This research received no external funding.

\section{Acknowledgments}

This work has been supported by the Spanish Ministry of Science and Innovation (PID2019104717RB-I00 Project) and the project entitled "Preparation and characterization of hydroxyapatite with controlled textural characteristics" financed by the Expert Fund Programmes by the Spanish of the Spanish Agency for International Development Cooperation (AECID). We thankfully acknowledge Dr. Prof. Eduardo Ruiz Hitzky for assistance with the CRTA equipment.

\section{Conflicts of Interest}

The authors declare no conflict of interest.

\section{References}

1. Gibson, I.R. 1.3.4A - Natural and Synthetic Hydroxyapatites. In: Biomaterials Science. Fourth Edition, Wagner, W.R.; Zhang, G.; Sakiyama-Elbert, S.E.; Yaszemski, M.J. Eds.; Academic Press, 2020; pp. 307317, https://doi.org/10.1016/B978-0-12-816137-1.00023-4.

2. de Groot, K.; Driessens, F.C.M.; Feenstra, L.; Griss, P.; Heimke, G.; Maltha, J.C.; van Mullem, P.J.; Woltgens, J.H.M. Bioceramics of Calcium Phosphate. 2018 ed.; CRC Press, Inc.: Boca Raton, FL, USA, 2018; pp. 79-142, https://doi.org/10.1201/9781351070133. 
3. Tian, Q.; Rivera-Castaneda, L.; Dunn, Z.S.; Liu, H. Bioceramics for Orthopaedic Device Applications: Hydroxyapatite. In: Nanobioceramics for healthcare applications. Thian, E.S.; Huang, J.; Aizawa, M. Eds.; World Scientific Publishing Europe Ltd: London, U.K., 2017; pp. 49-78, https://doi.org/10.1142/q0039.

4. Gutierrez-Prieto, S.J.; Perdomo-Lara, S.J.; Diaz-Peraza, J.M.; Sequeda-Castañeda, L.G. Analysis of In Vitro Osteoblast Culture on Scaffolds for Future Bone Regeneration Purposes in Dentistry. Advances in Pharmacological Sciences 2019, 2019, 9, https://doi.org/10.1155/2019/5420752.

5. Demirel, M.; Aksakal, B. Effect of porosity on the structure, mechanical properties and cell viability of new bioceramics as potential bone graft substitutes. Acta Bioeng. Biomech. 2018, 20, 11-22, https://doi.org/10.5277/ABB-01107-2018-02.

6. Nayak, A.K. Hydroxyapatite Synthesis Methodologies: An Overview. Int. J. Chem. Tech. Res. 2010, 2, 903907, https://doi.org/10.1016/j.actbio.2010.01.036.

7. Gomes, D.S.; Santos, A.M.C.; Neves, G.A.; Menezes, R.R. A brief review on hydroxyapatite production and use in biomedicine. Cerâmica 2019, 65, 282-302, http://dx.doi.org/10.1590/0366-69132019653742706.

8. Harun, W.S.W.; Asri, R.I.M.; Alias, J.; Zulkifli, F.H.; Kadirgama, K.; Ghani, S.A.C.; Shariffuddin, J.H.M. A comprehensive review of hydroxyapatite-based coating adhesion on metallic biomaterials. Ceram. Int. 2018, 44, 1250-1268, https://doi.org/10.1016/j.ceramint.2017.10.162.

9. Safarzadeh, M.; Ramesh, S.; Tan, C.Y.; Chandran, H.; Ching, Y.C.; Noor, A.F.M.; Krishnasamy, S.; Teng, W.D. Sintering behaviour of carbonated hydroxyapatite prepared at different carbonate and phosphate ratios. Bol. Soc. Esp. Ceram. V. 2020, 59, 73-80, https://doi.org/10.1016/j.bsecv.2019.08.001.

10. Yelten-Yilmaz, A.; Yilmaz, S. Wet chemical precipitation synthesis of hydroxyapatite (HA) powders. Ceram. Int. 2018, 44, 9703-9710, https://doi.org/10.1016/j.ceramint.2018.02.201.

11. Ulfyana, D.; Anugroho, F.; Sumarlan, S.H.; Wibisono, Y. Bioceramics synthesis of hydroxyapatite from red snapper fish scales biowaste using wet chemical precipitation route. IOP Conference Series: Earth and Environmental Science 2018, 131, https://doi.org/10.1088/1755-1315/131/1/012038.

12. Subramanian, R.; Sathish, S.; Murugan, P.; Mohamed Musthafa, A.; Elango, M. Effect of piperine on size, shape and morphology of hydroxyapatite nanoparticles synthesized by the chemical precipitation method. $J$. King Saud Univ. Sci. 2019, 31, 667-673, https://doi.org/10.1016/j.jksus.2018.01.002.

13. Mohd Pu'ad, N.A.S.; Abdul Haq, R.H.; Mohd Noh, H.; Abdullah, H.Z.; Idris, M.I.; Lee, T.C. Synthesis method of hydroxyapatite: A review. Materials Today: Proceedings 2020, 29, 233-239, https://doi.org/10.1016/j.matpr.2020.05.536.

14. Grigoraviciute-Puroniene, I.; Tanaka, Y.; Vegelyte, V.; Nishimoto, Y.; Ishikawa, K.; Kareiva, A. A novel synthetic approach to low-crystallinity calcium deficient hydroxyapatite. Ceram. Int. 2019, 45, 1562015623. https://doi.org/10.1016/j.ceramint.2019.05.072.

15. Moreno-Perez, B.; Matamoros-Veloza, Z.; Rendon-Angeles, J.C.; Yanagisawa, K.; Onda, A.; PérezTerrazas, J.E.; Mejia-Martínez, E.E.; Díaz, O.B.; Rodríguez-Reyes, M. Synthesis of silicon-substituted hydroxyapatite using hydrothermal process. Bol. Soc. Esp. Ceram. V. 2020, 59, 50-64, https://doi.org/10.1016/j.bsecv.2019.07.001.

16. Qi, M.-L.; Yao, S.; Liu, X.-C.; Wang, X.; Cui, F. Nanosheet-assembled carbonated hydroxyapatite microspheres prepared by an EDTA-assisted hydrothermal homogeneous precipitation route. Cryst. Eng. Comm. 2020, 22, 2884-2888, https://doi.org/10.1039/d0ce00305k.

17. Zhang, X.; Zhang, L.; Li, Y.; Hua, Y.; Li, Y.; Li, W.; Li, W. Template-assisted, Sol-gel Fabrication of Biocompatible, Hierarchically Porous Hydroxyapatite Scaffolds. Materials 2019, 12, https://doi.org/10.3390/ma12081274.

18. Mawuntu, V.J.; Yusuf, Y. Porous structure engineering of bioceramic hydroxyapatite-based scaffolds using PVA, PVP, and PEO as polymeric porogens. J. Asian Ceram. Soc. 2019, 7, 161-169, https://doi.org/10.1080/21870764.2019.1595927.

19. Poovendrana, K.; Wilson, K.S.J. Amalgamation and characterization of porous hydroxyapatite bio ceramics at two various temperatures. Mat. Sci. Semicon. Proc. 2019, 100, 255-261, https://doi.org/10.1016/j.mssp.2019.05.006.

20. Liu, D.M.; Troczynski, T.; Tseng, W.J. Water-based sol-gel synthesis of hydroxyapatite: process development. Biomaterials 2001, 22, 1721-1730, https://doi.org/10.1016/S0142-9612(00)00332-X.

21. Liu, D.M.; Yang, Q.; Troczynski, T.; Tseng, W.J. Structural evolution of sol-gel-derived hydroxyapatite. Biomaterials 2002, 23, 1679-1687, https://doi.org/10.1016/S0142-9612(01)00295-2.

22. Ishikawa, K.; Garskaite, E.; Kareiva, A. Sol-gel synthesis of calcium phosphate-based biomaterials-A review of environmentally benign, simple, and effective synthesis routes. J. Sol-Gel Sci. Techn. 2020, 94, 551-572, https://doi.org/10.1007/s10971-020-05245-8.

23. Pattanayak, D.K.; Dash, R.; Prasad, R.C.; Rao, B.T.; Rama Mohan, T.R. Synthesis and sintered properties evaluation of calcium phosphate ceramics. Mater. Sci. Eng. C 2007, 27, 684-690, https://doi.org/10.1016/j.msec.2006.06.021.

24. Mezahi, F.Z.; Oudadesse, H.; Harabi, A.; Lucas-Girot, A.; Le Gal, Y.; Chaair, H.; Cathelineau, G. Dissolution kinetic and structural behaviour of natural hydroxyapatite vs. thermal treatment: Comparison to synthetic hydroxyapatite. J. Therm. Anal. Calorim. 2009, 95, 21-29, https://doi.org/10.1007/s10973-0089065-4. 
25. Rouquerol, J. Thermal Analysis | Sample-Controlled Techniques. In: Encyclopedia of Analytical Science. Third Edition; Worsfold, P.; Poole, C.; Townshend, A.; Miró, M. Eds.; Academic Press: Oxford, 2019; pp. 17-32, https://doi.org/10.1016/B978-0-12-409547-2.14463-4.

26. Rouquerol, J.; Sorensen, O.T. General Introduction to Sample-Controlled Thermal Analysis (SCTA). In: Hot Topics in Thermal Analysis and Calorimetry - Sample Controlled Thermal Analysis Origin, Goals, Multiple Forms, Applications and Future. Sørensen, O.T.; Rouquerol, J. Eds.; Springer: Boston, MA, USA, 2003; pp. 1-7, https://doi.org/10.1007/978-1-4757-3735-6_1.

27. Alcalá, M.D.; Gotor, F.J.; Pérez-Maqueda, L.A.; Real, C.; Dianez, M.J.; Criado, J.M. Constant Rate Thermal Analysis (CRTA) as a tool for the synthesis of materials with controlled texture and structure. J. Therm. Anal. Calorim. 1999, 56, 1447-1452, https://doi.org/10.1023/A:1010187313720.

28. Rouquerol, J.; Rouquerol, F.; Llewellyn, P.; Maurin, G.; Sing, K. Adsorption by Metal Oxides. In Adsorption by Powders and Porous Solids, 2nd ed.; Academic Press: London, U.K., 2012; pp. 393-465. https://doi.org/10.1016/C2010-0-66232-8.

29. Locardi, B.; Pazzaglia, U.E.; Gabbi, C.; Profilo, B. Thermal behaviour of hydroxyapatite intended for medical applications. Biomaterials 1993, 14, 437-441, https://doi.org/10.1016/0142-9612(93)90146-S.

30. Gross, K.A.; Gross, V.; Berndt, C.C. Thermal analysis of amorphous phases in hydroxyapatite coatings. $J$. Am. Ceram. Soc. 1998, 81, 106-112, https://doi.org/10.1111/j.1151-2916.1998.tb02301.x.

31. Liao, C.J.; Lin, F.H.; Chen, K.S.; Sun, J.S. Thermal decomposition and reconstitution of hydroxyapatite in air atmosphere. Biomaterials 1999, 20, 1807-1813, https://doi.org/10.1016/S0142-9612(99)00076-9.

32. Döbelin, N.; Maazouz, Y.; Heuberger, R.; Bohner, M.; Armstrong, A.A.; Wagoner Johnson, A.J.; Wanner, C. A thermodynamic approach to surface modification of calcium phosphate implants by phosphate evaporation and condensation. J. Eur. Ceram. Soc. 2020, 40, 6095-6106, https://doi.org/10.1016/j.jeurceramsoc.2020.07.028.

33. Rabadjieva, D.; Gergulova, R.; Titorenkova, R.; Tepavitcharova, S.; Dyulgerova, E.; Balarew, C.; Petrov, O. Biomimetic transformations of amorphous calcium phosphate: Kinetic and thermodynamic studies. $J$. Mater. Sci. Mater. Med. 2010, 21, 2501-2509, https://doi.org/10.1007/s10856-010-4103-8.

34. Anastasios, I.M.; Tiverios, C.V. A calorimetric study of the temperature effect on Calcium Phosphate precipitation. J. Therm. Anal. Calorim. 2010, 99, 785-789, https://doi.org/10.1007/s10973-009-0357-0.

35. Barua, E.; Das, A.; Pamu, D.; Deoghare, A.B.; Deb, P.; Lala, S.D.; Chatterjee, S. Effect of thermal treatment on the physico-chemical properties of bioactive hydroxyapatite derived from caprine bone bio-waste. Ceram. Int. 2019, 45, 23265-23277, https://doi.org/10.1016/j.ceramint.2019.08.023.

36. Tõnsuaadu, K.; Gross, K.A.; Pluduma, L.; Veiderma, M. A review on the thermal stability of calcium apatites. J. Therm. Anal. Calorim. 2012, 110, 647-659, https://doi.org/10.1007/s10973-011-1877-y.

37. Sun, R.; Chen, K.; Liao, Z.; Meng, N. Controlled synthesis and thermal stability of hydroxyapatite hierarchical microstructures. Mater. Res. Bull. 2013, 48, 1143-1147, https://doi.org/10.1016/j.materresbull.2012.12.013.

38. Sofronia, A.M.; Baies, R.; Anghel, E.M.; Marinescu, C.A.; Tanasescu, S. Thermal and structural characterization of synthetic and natural nanocrystalline hydroxyapatite. Mater. Sci. Eng. C 2014, 43, 153163, https://doi.org/10.1016/j.msec.2014.07.023.

39. Romero Salvador, A.; García Calvo, E. Kinetic analysis of non-isothermal solid decomposition reactions. An approach to the treatment of experimental data. Thermochim. Acta 1992, 203, 67-76, https://doi.org/10.1016/0040-6031(92)85185-X.

40. Romero Salvador, A.; García Calvo, E. Kinetic analysis of TG data, discrimination of integral models. Thermochim. Acta 1984, 73, 101-108, https://doi.org/10.1016/0040-6031(84)85180-1.

41. Romero Salvador, A.; Garcia, C.E. Kinetic analysis of TG data: study of calcium oxalate monohydrate dehydration with a non-separable variables model. Thermochim. Acta 1986, 104, 71-76, https://doi.org/10.1016/0040-6031(86)85184-X.

42. Koga, N.; Sestak, J.; Simon, P. Some Fundamental and Historical Aspects of Phenomenological Kinetics in the Solid State Studied by Thermal Analysis. In: Thermal Analysis of Micro, Nano- and Non-Crystalline Materials, Hot Topics in Thermal Analysis and Calorimetry. Sestak, J.; Simon, P. Eds.; Springer, Dordrecht: Germany, 2013; pp. 1-28, https://doi.org/10.1007/978-90-481-3150-1_1.

43. Khawam, A.; Flanagan, D.R. Solid-State Kinetic Models: Basics and Mathematical Fundamentals. J. Phys. Chem. B 2006, 110, 17315-17328, https://doi.org/10.1021/jp062746a.

44. Achar, B.N.N.; Brindley, G.W.; Sharp, J.H. Kinetics of solids. Proceedings of the International Clay Conference, Jerusalem, Israel, Volume 2, 1966; pp. 67.

45. Jerez, A. A modification to the Freeman and Carroll method for the analysis of the kinetics of non-isothermal processes. J. Therm. Anal. Calorim. 1983, 26, 315-318, https://doi.org/10.1007/BF01913218.

46. Fowler, B.O. Infrared studies of apatites I. Vibrational assignments for calcium, strontium, and barium hydroxyapatites utilizing isotopic substitution. Inorg. Chem. 1974, 13, 194-206, https://doi.org/10.1021/ic50131a039.

47. Fowler, B.O. Infrared studies of apatites II. Preparation of normal and isotopically substituted calcium, strontium, and barium hydroxyapatites and spectra-structure-composition correlations. Inorg. Chem. 1974, 13, 207-214, https://doi.org/10.1021/ic50131a040. 
48. Pleshko, N.; Boskey, A.; Mendelsohn, R. Novel infrared spectroscopic method for the determination of crystallinity of hydroxyapatyte minerals. Biophys. J. 1991, 60, 786-793, https://doi.org/10.1016/S00063495(91)82113-0.

49. Antonakos, A.; Liarokapis, E.; Leventouri, T. Micro-Raman and FTIR studies of synthetic and natural apatites. Biomaterials 2007, 28, 3043-3054, https://doi.org/10.1016/j.biomaterials.2007.02.028.

50. Mazumder, S.; Mukberjee, B. Quantitative determination of amorphous content in bioceramic hydroxyapatite (HA) using x-ray powder diffraction data. Mater. Res. Bull. 1995, 30, 1439-1445, https://doi.org/10.1016/0025-5408(95)00124-7.

51. Landi, E.; Tampieri, A.; Celotti, G.; Sprio, S. Densification behavior and mechanisms of synthetic hydroxyapatites. J. Eur. Ceram. Soc. 2000, 20, 2377-2387, https://doi.org/10.1016/S0955-2219(00)001540 .

52. Kostov-Kytina, V.V.; Dyulgerova, E.; Ilieva, R.; Petkova, V. Powder X-ray diffraction studies of hydroxyapatite and $\beta$-TCP mixtures processed by high energy dry milling. Ceram. Int. 2018, 44, 8664-8671, https://doi.org/10.1016/j.ceramint.2018.02.094. 